\title{
Tecido empresarial algarvio: Demografia, crescimento e sobrevivência
}

\section{Algarve's entrepreneurial fabric: Demography, growth and survival}

\author{
Elsa de Morais Sarmento \\ Universidade de Aveiro, Portugal \\ elsa.sarmento@gmail.com \\ Alcina Nunes \\ Instituto Politécnico de Bragança e GEMF - Universidade de Coimbra \\ alcina@ipb.pt
}

\begin{abstract}
Resumo
Este artigo dedica-se a analisar a dinâmica empresarial do conjunto de empresas empregadoras inseridas no tecido empresarial algarvio ao longo de duas décadas (1985-2007). A partir da desagregação regional, a demografia das empresas algarvias é analisada numa ótica setorial, por dimensão empresarial e intensidade de crescimento, tendo em conta a taxa de criação de empresas, o emprego, a intensidade de crescimento, a longevidade e a probabilidade de sobrevivência de empresas. Em 2007, apenas três das regiões NUTII apresentavam uma taxa de criação de empresas acima da média nacional, sendo o Algarve, a partir do ano 2000, a região nacional com a maior taxa de criação de empresas. Esta é também a região com o mais elevado crescimento do número de empresas, verificando-se simultaneamente uma elevada volatilidade empresarial em consequência da elevada proporção de pequenas e médias empresas. Esta evidência está relacionada com o modelo de especialização regional, que se tem concentrado nos sectores de serviços e construção ao longo do período.
\end{abstract}

Palavras-chave: demografia empresarial; empreendedorismo; sobrevivência empresarial; empresas de elevado crescimento; Algarve.

\begin{abstract}
This paper offers a two decades' (1985-2007) perspective of employer enterprises' demography dynamics in the Portuguese region of the Algarve. Departing from the NUTII regional disaggregation, this region's firm demography is further broken down by sector, size and growth intensity, during the analysis of firm creation, employment, high-growth firms, longevity and survival probability. By 2007, only three NUTII regions displayed a rate of firm creation above the national average, with Algarve being the region in the country with the highest rate of firm creation, after the year 2000. Algarve also displays the highest rate of growth of employer enterprises, suffering however from considerable firm turbulence due to its high share of SME. These findings are related to the regional specialization model, as Algarve's firms have been shown to be increasingly concentrated in the services and construction sectors throughout the period.
\end{abstract}

Keywords: firm demography; entrepreneurship; firm survival; high-growth firms; Algarve.

\section{Introdução}

O estudo do empreendedorismo em geral, e da demografia e dinâmica empresarial em particular, tem suscitado um interesse crescente, multiplicando-se os estudos empíricos tanto internacionais como nacionais - que se debruçam sobre o fenómeno. Este deve-se não só ao desenvolvimento de conceitos harmonizados nesta área (Ahmad e Seymor; 2008 e

Dos Algarves: A Multidisciplinary e-Journal, 28 - 2016.

ISBN 2182-5580 @ ESGHT-University of the Algarve, Portugal.

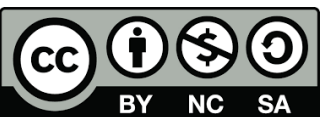

To cite this article: Sarmento, E.M. \& Nunes, A. (2016). Tecido empresarial algarvio: demografia, crescimento e sobrevivência. Dos Algarves: A Multidisciplinary e-Journal, 28, 45-67. doi: 10.18089/DAMeJ.2016.28.4 
Ahmad, 2006), como ao acesso a bases de dados longitudinais e ao desenvolvimento de técnicas de análise estatística que permitem um melhor aproveitamento da informação disponível. Este aspecto relaciona-se ainda com o interesse crescente por parte das instituições públicas quanto às questões do empreendedorismo e ao seu cruzamento com o crescimento e desenvolvimento económico a nível regional (Sternberg, 2012; Sarmento \& Nunes, 2011; Nunes \& Sarmento, 2010; Brixy \& Grotz, 2007; Armington \& Acs, 2002). A análise do fenómeno do empreendedorismo e da dinâmica empresarial tem vindo na última década, e de uma forma cada vez mais intensa, a ser aliada a processos de implementação de políticas de desenvolvimento económico regional e local um pouco por todo o mundo desenvolvido (Sternberg, 2012; Trettin \& Welter, 2011; Malecki, 2009) e em desenvolvimento (Naudé, Gries, Wood \& Meintjes, 2008).

Reconhece-se que são de diversa índole os fatores regionais determinantes da atividade empreendedora (Sternberg, 2010; Santarelli \& Vivarelli, 2007; Acs \& Storey, 2004). Apesar do estudo da dinâmica empresarial se concentrar tradicionalmente nos aspetos de criação de novas empresas, em detrimento de aspetos relacionados com a sobrevivência e encerramento de empresas (Nyström, 2007), são já diversos os estudos que se debruçam sobre estes últimos, relacionando-os com a atividade das empresas e com a sua localização geográfica (Carree, Verheul \& Santarelli, 2011). Kibler (2012) identifica vários estudos nos quais condições regionais, como o enquadramento económico e as características sócio demográficas locais, se tornam (co)determinantes da estrutura, recursos e capacidades suscetíveis de afetar o comportamento empreendedor, determinante último na criação de empresas. A proximidade a fontes de conhecimento, inovação e de capital humano qualificado é outro aspeto fundamental na análise das diferenças regionais do processo de criação de empresas (Batista \& Mendonça, 2010).

A investigação dedicada à dinâmica empresarial pós-criação de empresas é mais recente e parca sendo os estudos realizados na perspetiva regional ainda menos frequentes dadas as dificuldades em utilizar bases de dados regionais de boa qualidade, atuais, confiáveis e comparáveis (Sternberg, 2010; van Dijk \& Pellenbarg, 2000). Na última década surgiram vários estudos sobre a distribuição regional da criação de empresas, mas de facto, apenas recentemente se começaram a divulgar evidências de que as atividades empresariais não estão distribuídas equitativamente no espaço e que a sua probabilidade de sobrevivência pode depender da localização (Bosma \& Sternberg, 2014; Sternberg, 2010; Brixy \& Grotz, 2007; Nyström, 2007; Armington \& Acs, 2002). A maior acessibilidade a dados estatísticos individuais, num formato longitudinal e desagregados regionalmente, é uma das razões fundamentais que explica o seu aparecimento e desenvolvimento recentes (Brixy \& Grotz, 2007). No entanto, tem existido uma tomada de consciência de que uma análise regional da dinâmica empresarial pós-criação de empresas, através do acompanhamento do seu ciclo de crescimento, sobrevivência e encerramento, permite uma melhor identificação das oportunidades e ameaças que as empresas enfrentam no seu ambiente de proximidade. Carree, Verheul e Santarelli (2011) chamam a atenção para o facto de a sobrevivência das empresas poder ser mais elevada em regiões próximas dos (potenciais) clientes e fornecedores mas, também, em regiões com maior crescimento económico e capacidade de inovação e onde a concorrência numa determinada indústria não seja tão forte. Efetivamente, a estrutura industrial de uma região tem-se mostrado determinante na explicação de diferenças regionais entre as taxas de criação e encerramento de empresas (Nyström, 2007; 
Armington \& Acs, 2002). Todas estas hipóteses têm sido alvo de escrutínio empírico, não só por forma a melhor conhecer esta realidade empresarial mas, também, como forma de fundamentar a atuação da política regional. Brixy \& Grotz (2007) realçam que uma política regional estrutural deve focar-se não apenas em encorajar a criação de empresas mas, igualmente, em assegurar a sua permanência no mercado.

Em Portugal, existe uma extensa investigação dedicada à análise da dinâmica da atividade empresarial, que provém do acesso e utilização de uma base de dados importantíssima para a análise do tecido empresarial português, bem como do mercado de trabalho, os Quadros de Pessoal. Entre outros, destacam-se nesta área os trabalhos de Sarmento e Nunes (2012a), Geroski, Mata e Portugal (2010), Cabral (2007), Cabral e Mata (2003), Mata, Portugal e Guimarães (1995), Mata e Portugal (1994) e Mata (1993). São, no entanto, menos frequentes os trabalhos que se dedicam à análise regional e espacial. Entre estes destacam-se, na análise da dinâmica empresarial regional, o trabalho de Barbosa e Eiriz (2011) e de Nunes e Sarmento (2010) e, sobre o impacto da atividade empreendedora no crescimento económico e no emprego, os trabalhos de Batista e Preto (2011) e o de Batista, Escária e Madruga (2008).

O presente trabalho propõe-se analisar a região do Algarve, definida pelo conceito de NUT II. No conjunto das NUTII portuguesas, esta é uma região com características que importam salientar. O Algarve torna-se a partir de 2000 a região com a maior taxa de criação de empresas empregadoras do país. É, igualmente, a região com o mais elevado crescimento da população de empresas ao longo dos cerca de vinte anos sobre os quais versa este estudo. Estes factos suscitam por si só um interesse acrescido numa análise mais pormenorizada da região, de forma a melhor compreender este fenómeno. Assim, propõe-se uma análise mais aprofundada e crítica sobre a atividade empresarial do conjunto de empresas empregadoras na região do Algarve ao longo de mais de duas décadas (1985-2007), com recurso a uma base de dados concebida a partir dos Quadros de Pessoal, que adota a metodologia preconizada pela OCDE e Eurostat no Manual on Business Demography Statistics (Eurostat \& OCDE, 2007). A partir da dimensão regional analisam-se a longevidade, a dimensão empresarial, a probabilidade de sobrevivência, o emprego e o subconjunto de empresas formado pelas designadas "empresas de elevado crescimento" e "gazelas".

Este trabalho está estruturado em oito secções. Na próxima secção, descreve-se a importância económica do tecido empresarial algarvio no contexto do seu desenvolvimento regional. De seguida, da terceira à sétima secção, é elaborado o perfil das empresas empregadoras algarvias relativamente à criação, encerramento, dinâmica empresarial, emprego, intensidade de crescimento e sobrevivência de empresas, respetivamente. Finalmente, a secção oito conclui.

\section{A importância do tecido empresarial algarvio no desenvolvimento regional}

Apesar de este continuar a ser ainda um assunto amplamente debatido, a literatura na área vem salientando que a atividade empreendedora apresenta especificidades próprias inerentes ao espaço geográfico onde se insere. No entanto, é reconhecido que os efeitos benéficos da atividade empreendedora se tornam particularmente visíveis quando analisados sob uma ótica regional (Santarelli \& Vivarelli, 2007). Em particular, no que diz respeito às diferentes 
dotações regionais de fatores produtivos e capacidade de disseminação de conhecimento com efeitos, designadamente, na produtividade e emprego (Baumgartner, Pütz \& Seidl, 2013; Audretsch, Bönteb \& Keilbach, 2008; Audretsch, 2007).

Se o efeito direto da criação de novas empresas (nomeadamente através da criação de novos empregos) pode ter um efeito discutível no desenvolvimento regional, efeitos indiretos do fenómeno empreendedor - inovação, produtividade e crescimento da oferta de produtos e serviços e acréscimos da eficiência na produção e gestão das novas e empresas existentes, por exemplo - mostram possuir uma importância fundamental no desenvolvimento económico regional. De facto, a pertinência da análise de indicadores relativos à dinâmica empresarial regional deve-se ao facto do tecido empresarial ser responsável por uma parte substancial da geração de riqueza a nível local. No caso concreto do Algarve, existe uma correlação positiva elevada entre 2003 e 2007, entre a taxa de crescimento do número de empresas ativas e a taxa de crescimento real do Produto Interno Bruto (PIB) contabilizado para a região NUT Algarve, após um período de alguma inconstância na relação (Figura 1).

Figura 1. Relação entre o n..$^{\circ}$ de empresas ativas e o PIB da região Algarve entre 1996 e 2007

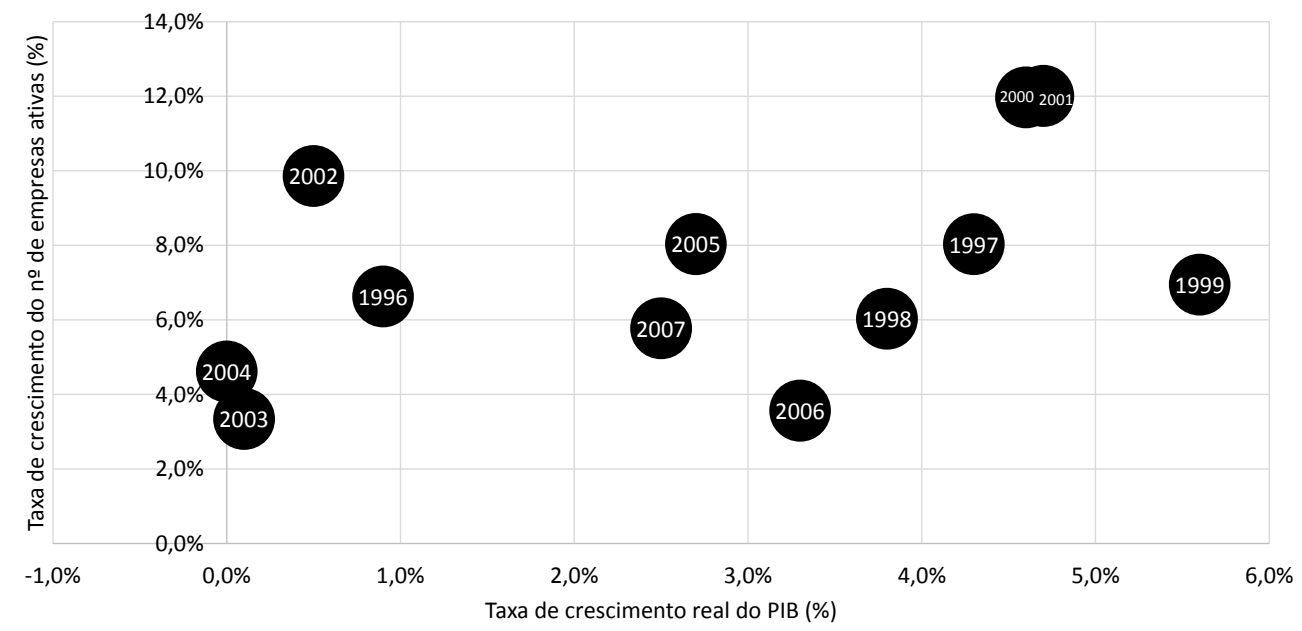

Fonte: Elaboração própria, com base nos dados dos Quadros de Pessoal e INE (2008).

Por outro lado, a densidade empresarial, calculada através do quociente entre a população de empresas empregadoras e o total da população ativa na região, oferece um contraste interessante entre a dinâmica de crescimento do tecido empresarial e a da população de uma região. O Algarve é a segunda região com maior densidade empresarial de empresas empregadoras, a seguir ao Alentejo, superando a densidade nacional (Figura 2).

Face à população ativa que detém, o Algarve apresenta um crescimento de empresas considerável e sustentado ao longo de uma década. O fenómeno é explicado (sobretudo a partir de 2000) em grande parte pela especialização setorial na construção e nos serviços, nomeadamente respeitantes ao turismo. No que diz respeito à criação de novas empresas, o Algarve apresenta a maior densidade regional do país, no período após 2001. 
Figura 2. Densidade empresarial na região do Algarve e em Portugal

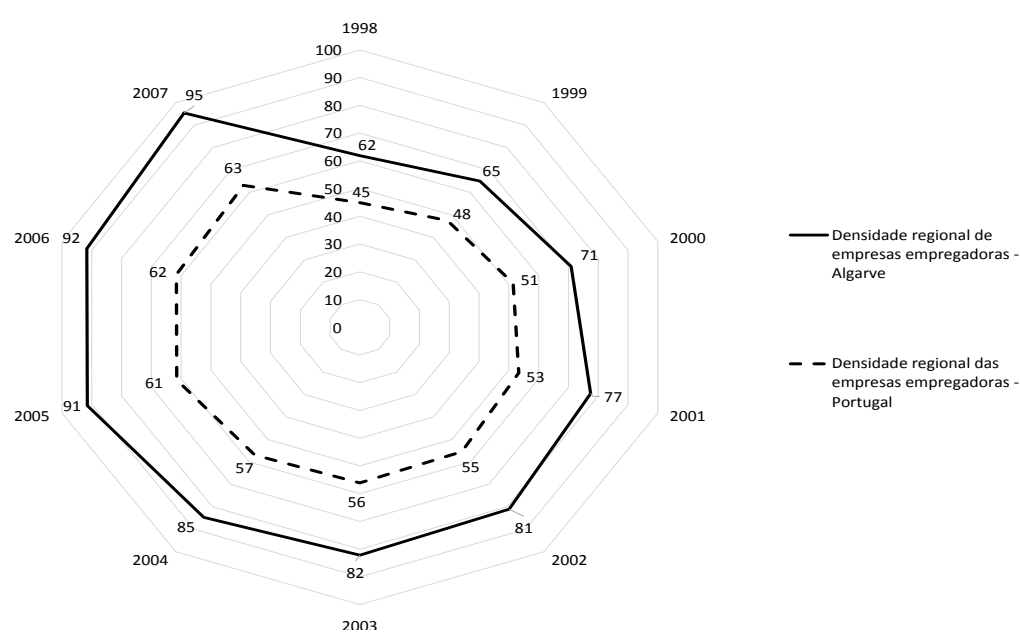

Fonte: Elaboração própria, com base nos Quadros de Pessoal de acordo com as definições do Manual of Business Demography Statistics (Eurostat \& OCDE, 2007).

\section{Empresas empregadoras no contexto empresarial algarvio em comparação com os valores para o território nacional}

A utilização de uma base de dados específica no domínio do empreendedorismo, baseada nos Quadros de Pessoal, ${ }^{1}$ que decorre da aplicação da metodologia proposta pelo Eurostat e pela OCDE (Eurostat \& OCDE, 2007), permite obter de forma consistente e fundamentada um conjunto de empresas portuguesas que empregam pelo menos um trabalhador remunerado e que operam no mercado formal em Portugal. Estas empresas constituem a grande fonte de criação de emprego (dependente) em Portugal. Face à metodologia adotada, os indicadores apurados tornam-se comparáveis não só a nível regional e nacional (OCDE, 2009 \& 2008) sendo que a riqueza e desagregação longitudinal da informação contida nesta base de dados permitem decompor a análise em diversas dimensões, como a regional, dimensional e de sobrevivência.

A população de empresas empregadoras ativas compreende todas as empresas que remuneram pelo menos um trabalhador no ano da sua criação. Para evitar problemas de contabilização e duplicação ${ }^{2}$ o Eurostat e a OCDE (2007) recomendam que se verifiquem dois anos de atividade, antes de se considerar efetivamente como criação, o surgimento de uma nova empresa na base de dados. Esta exigência conduz a que a identificação de novas empresas se inicie dois anos após o período inicial em que a empresa surgiu na base de dados. Esta é a razão pela qual a criação de empresas é contabilizada a partir de 1987 em lugar de 1985, ano de início do estudo, e para o qual se considera que a recolha sistemática de dados

\footnotetext{
${ }^{1}$ A base de dados Quadros de Pessoal constitui uma base de dados nacional, proveniente do Ministério do Trabalho e da Segurança Social, que fornece informação sobre empresas, estabelecimentos e empregados. Foram incluídas no estudo todas as empresas que cumprem estritamente os requisitos da metodologia adotada, ou seja, empresas empregadoras com pelo menos um trabalhador integrado no sistema de Segurança Social.

${ }^{2}$ Nomeadamente no que diz respeito a empresas já existentes mas que se encontram "adormecidas" num determinado ano e cuja reativação é detetada na base de dados, posteriormente.
} 
permite a elaboração de um estudo sem falhas ou lacunas resultantes de deficiências metodológicas na recolha desses dados. ${ }^{3}$ Por outro lado, as mesmas instituições estatísticas internacionais consideram que os encerramentos ocorrem quando as empresas deixam de estar presentes na base de dados durante pelo menos dois anos, de forma a evitar intermitências de entradas e saídas de empresas. Assim, a aplicação da metodologia para o cálculo de indicadores de empreendedorismo recomenda, explicitamente, a verificação do não aparecimento da empresa na base de dados, nos dois anos seguintes ao período de referência, de forma a permitir a distinção entre encerramentos efetivos e reativações de empresas. Por este motivo, o período de análise termina em 2005 de forma a garantir que as empresas que encerraram em 2005 não subsistem na base de dados nos dois anos subsequentes. Em 2008, entra em vigor a classificação CAE Rev.3 o que quebra a série estatística de dados em 2007. Este acontecimento não permite uma perfeita compatibilidade e, portanto, comparabilidade com a série de dados disponíveis entre 1985 e 2007 e em análise, neste trabalho.

A Tabela 1 contém o número de empresas ativas, com pelo menos um trabalhador, entre 1985 e 2007, bem como o seu peso no total de empresas ativas da economia portuguesa, por três classes de dimensão ${ }^{4}$ : empresas com menos de dez trabalhadores, empresas que empregam entre 10 e 249 trabalhadores e empresas de elevada dimensão que empregam 250 trabalhadores ou mais. Para além destes dados, é também apresentada a dimensão média das empresas e a proporção de empresas com menos de dez trabalhadores, na região e na economia portuguesa como um todo.

\footnotetext{
${ }^{3}$ Note-se que o regime legal dos Quadros de Pessoal foi instituído pelo Decreto-Lei n. ${ }^{\circ}$ 479/76, de 16 de Junho, que tornou obrigatório o preenchimento anual dos mapas "Quadros de Pessoal.

${ }^{4}$ Note-se que, ao longo deste trabalho, a dimensão das empresas será medida pelo número de trabalhadores que empregam.
} 
Tabela 1. Evolução do total de empresas, trabalhadores e respetiva proporção no total nacional, por dimensão e dimensão média das empresas

\begin{tabular}{|c|c|c|c|c|c|c|c|c|c|c|c|}
\hline \multirow{3}{*}{ Anos } & \multirow{3}{*}{$\begin{array}{c}\text { № de } \\
\text { empresas } \\
\text { ativas no } \\
\text { Algarve }\end{array}$} & \multicolumn{4}{|c|}{$\begin{array}{l}\text { Peso das empresas algarvias no conjunto de } \\
\text { empresas nacionais (\%), por dimensão }\end{array}$} & \multicolumn{3}{|c|}{$\begin{array}{c}\text { Dimensão média das empresas ( } \mathrm{n} \text { - } \\
\text { de trabalhadores) }\end{array}$} & \multicolumn{3}{|c|}{$\begin{array}{l}\text { Proporção de empresas com } \\
\quad<10 \text { trabalhadores }(\%)\end{array}$} \\
\hline & & & & & & Portugal & Algarve & Diferença & Portugal & Algarve & Diferença \\
\hline & & Total & $1-9$ & $10-249$ & +250 & (1) & (2) & $(3)=(1)-(2)$ & (4) & (5) & $(6)=(4)-(5)$ \\
\hline 1985 & 3081 & 3,02 & 3,21 & 2,55 & 1,14 & 13,10 & 11,31 & 1,79 & 73,07 & 77,67 & $-4,60$ \\
\hline 1986 & 3269 & 3,06 & 3,27 & 2,52 & 1,05 & 14,31 & 10,82 & 3,49 & 73,74 & 78,77 & $-5,03$ \\
\hline 1987 & 3657 & 3,30 & 3,53 & 2,69 & 0,93 & 16,86 & 10,01 & 6,85 & 73,90 & 79,11 & $-5,21$ \\
\hline 1988 & 4353 & 3,55 & 3,81 & 2,82 & 1,33 & 13,86 & 9,87 & 3,98 & 74,54 & 80,01 & $-5,47$ \\
\hline 1989 & 5557 & 4,05 & 4,43 & 2,94 & 0,77 & 28,12 & 8,49 & 19,63 & 75,38 & 82,49 & $-7,11$ \\
\hline 1990 & 5700 & 4,06 & 4,46 & 2,89 & 1,10 & 19,56 & 8,48 & 11,08 & 75,24 & 82,68 & $-7,44$ \\
\hline 1991 & 6363 & 4,28 & 4,72 & 2,94 & 1,08 & 16,03 & 8,19 & 7,84 & 75,97 & 83,77 & $-7,80$ \\
\hline 1992 & 6979 & 4,38 & 4,84 & 2,92 & 1,12 & 13,78 & 7,87 & 5,91 & 76,71 & 84,73 & $-8,01$ \\
\hline 1993 & 7293 & 4,40 & 4,83 & 2,92 & 1,08 & 13,92 & 7,43 & 6,50 & 77,81 & 85,45 & $-7,64$ \\
\hline 1994 & 8558 & 4,64 & 5,05 & 3,09 & 1,25 & 12,20 & 6,66 & 5,53 & 79,82 & 86,75 & $-6,93$ \\
\hline 1995 & 8994 & 4,68 & 5,07 & 3,10 & 1,23 & 11,93 & 6,51 & 5,41 & 80,71 & 87,40 & $-6,69$ \\
\hline 1996 & 9590 & 4,85 & 5,24 & 3,21 & 1,15 & 10,91 & 6,41 & 4,49 & 81,35 & 87,82 & $-6,47$ \\
\hline 1997 & 10360 & 4,85 & 5,23 & 3,20 & 1,14 & 12,29 & 6,28 & 6,01 & 81,65 & 88,04 & $-6,39$ \\
\hline 1998 & 10985 & 4,80 & 5,14 & 3,29 & 1,24 & 11,09 & 6,28 & 4,81 & 82,05 & 87,86 & $-5,81$ \\
\hline 1999 & 11748 & 4,81 & 5,11 & 3,46 & 1,55 & 9,56 & 6,40 & 3,16 & 82,16 & 87,30 & $-5,14$ \\
\hline 2000 & 13159 & 4,90 & 5,19 & 3,54 & 1,31 & 10,51 & 6,27 & 4,24 & 82,92 & 87,80 & $-4,87$ \\
\hline 2001 & 14734 & 5,19 & 5,44 & 4,05 & 1,34 & 9,51 & 6,48 & 3,03 & 82,70 & 86,66 & $-3,96$ \\
\hline 2002 & 16187 & 5,40 & 5,64 & 4,23 & 1,69 & 7,88 & 6,14 & 1,74 & 83,44 & 87,16 & $-3,72$ \\
\hline 2003 & 16728 & 5,46 & 5,67 & 4,36 & 1,89 & 6,94 & 6,16 & 0,78 & 83,99 & 87,33 & $-3,35$ \\
\hline 2004 & 17500 & 5,59 & 5,81 & 4,48 & 1,47 & 8,71 & 6,09 & 2,62 & 84,32 & 87,58 & $-3,26$ \\
\hline 2005 & 18906 & 5,55 & 5,74 & 4,53 & 1,69 & 7,54 & 6,05 & 1,49 & 84,79 & 87,73 & $-2,94$ \\
\hline 2006 & 19580 & 5,69 & 5,88 & 4,66 & 2,02 & 6,19 & 6,07 & 0,12 & 84,91 & 87,78 & $-2,87$ \\
\hline 2007 & 20711 & 5,84 & 6,00 & 4,97 & 2,08 & 6,11 & 6,19 & $-0,08$ & 84,85 & 87,23 & $-2,38$ \\
\hline $\begin{array}{c}\text { Taxa de } \\
\text { crescimento } \\
\text { médio (\%) }\end{array}$ & 9,05 & 3,04 & 2,88 & 3,1 & 2,77 & $-3,41$ & $-2,70$ & -- & 0,68 & 0,53 & --- \\
\hline
\end{tabular}

Fonte: Elaboração própria, com base nos Quadros de Pessoal de acordo com as definições do Manual of Business Demography Statistics (Eurostat \& OCDE, 2007).

No período considerado, o número absoluto de empresas empregadoras ativas, no Algarve, cresceu consideravelmente - de cerca de 3.000, em 1985 (3\% do total de empresas nacionais), para quase 21.000 , em 2007 ( $6 \%$ do total de empresas no território português), o que perfaz um crescimento médio de cerca de $9 \%$ ao ano. No total nacional, o tecido de empresas empregadoras no Algarve representava, em 2007, 6\% das empresas nacionais. Apesar de tudo, este indicador melhorou significativamente em vinte e dois anos com a proporção de empresas instaladas no Algarve a crescerem cerca de 3\% ao ano relativamente ao total nacional. Este acréscimo do peso das empresas algarvias deve-se, fundamentalmente, a uma maior criação de emprego nas empresas mais pequenas (com menos de dez trabalhadores), que se tornaram mais abundantes. Efetivamente, o número de pequenas empresas aumentou ao longo destes 22 anos (78\% em 1985 e 87\% em 2007), em linha com o que se verificou no país. $\mathrm{Na}$ região algarvia predominam as empresas com menos de dez trabalhadores, sendo o diferencial de dimensão face à média nacional, sempre desfavorável à região.

Entre 1985 e 2007, o conjunto de empresas algarvias viu diminuir o número de empregados médios de onze trabalhadores, em média, registados por empresa passou-se para cerca de seis trabalhadores, valor médio idêntico ao nacional. Existe uma tendência evidente para uma redução da dimensão empresarial - em vinte e dois anos, as empresas perdem, em média, o equivalente a cerca de cinco trabalhadores, valor no entanto inferior à média nacional de sete trabalhadores. O fenómeno de perda de dimensão é, também, visível quando se compara a dimensão de uma empresa no momento da sua criação, com a sua dimensão no momento do encerramento, traduzindo esta diferença o diferencial de 
crescimento, ou seja, a capacidade de crescimento médio em número de trabalhadores (Tabela 2).

Tabela 2. Dimensão média de novas empresas e de empresas que encerram atividade, no Algarve e em Portugal

\begin{tabular}{|c|c|c|c|c|c|c|c|c|}
\hline \multirow{3}{*}{ Anos } & \multicolumn{3}{|c|}{ Dimensão média de novas empresas } & \multicolumn{3}{|c|}{ Dimensão média de empresas que encerram } & \multicolumn{2}{|c|}{$\begin{array}{l}\text { Diferencial de crescimento em } \\
\text { termos de dimensão média }\end{array}$} \\
\hline & Portugal & Algarve & Diferença & Portugal & Algarve & Diferença & Portugal & Algarve \\
\hline & $(1)$ & $(2)$ & $(3)=(1)-(2)$ & (4) & (5) & $(6)=(4)-(5)$ & $(6)=(1)-(4)$ & $(7)=(2)-(5)$ \\
\hline 1986 & & & & 6,48 & 5,66 & 0,82 & & \\
\hline 1987 & 5,41 & 4,69 & 0,71 & 6,71 & 5,08 & 1,62 & 1,30 & 0,39 \\
\hline 1988 & 5,58 & 5,29 & 0,29 & 5,97 & 6,14 & $-0,17$ & 0,39 & 0,85 \\
\hline 1991 & 5,83 & 4,41 & 1,41 & 6,59 & 4,08 & 2,51 & 0,76 & $-0,33$ \\
\hline 1992 & 5,10 & 3,97 & 1,13 & 6,36 & 4,51 & 1,85 & 1,26 & 0,54 \\
\hline 1993 & 5,23 & 3,81 & 1,42 & 8,24 & 4,64 & 3,60 & 3,01 & 0,83 \\
\hline 1994 & 6,06 & 4,10 & 1,96 & 5,42 & 3,79 & 1,63 & $-0,64$ & $-0,31$ \\
\hline 1995 & 4,11 & 3,36 & 0,75 & 5,24 & 3,61 & 1,63 & 1,13 & 0,25 \\
\hline 1996 & 4,10 & 3,34 & 0,76 & 4,88 & 3,44 & 1,44 & 0,78 & 0,09 \\
\hline 2002 & 3,88 & 3,17 & 0,71 & 4,40 & 2,95 & 1,45 & 0,52 & $-0,22$ \\
\hline 2003 & 3,97 & 3,27 & 0,69 & 4,00 & 2,86 & 1,14 & 0,04 & $-0,41$ \\
\hline 2004 & 3,82 & 3,34 & 0,48 & 3,74 & 2,88 & 0,86 & $-0,08$ & $-0,46$ \\
\hline 2005 & 4,03 & 3,48 & 0,55 & 3,59 & 2,94 & 0,65 & $-0,45$ & $-0,54$ \\
\hline 2006 & 3,38 & 3,22 & 0,16 & & & & & \\
\hline 2007 & 3,37 & 2,99 & 0,38 & & & & & \\
\hline
\end{tabular}

Fonte: Elaboração própria, com base nos Quadros de Pessoal de acordo com as definições do Manual of Business Demography Statistics (Eurostat \& OCDE, 2007).

No momento em que são criadas e no momento em que encerram, as empresas algarvias continuam, em média, a ser mais pequenas do que a média nacional. Assiste-se, também, a um fenómeno de redução do diferencial de dimensão entre estes dois momentos de vida e morte das empresas, ao qual a região algarvia não fica imune. Em dez anos, as novas empresas são criadas com menos dois trabalhadores, em média, enquanto estas encerram com menos três trabalhadores, em 2007 relativamente a 1987. A partir de 2005, as empresas passam a encerrar, em média, com um número de trabalhadores inferior ao que possuíam no momento da sua criação. O outsourcing e a automatização de muitas tarefas, nomeadamente com o advento das tecnologias de informação, contribuíram substancialmente para menores necessidades de pessoal, nomeadamente em setores mais intensivos em trabalho, como o caso dos serviços. Contudo, a dimensão inicial das empresas algarvias reduz-se, mas menos que a média nacional, o que pode estar relacionado com o facto de essas novas empresas serem empresas já criadas com uma dimensão inferior à da média de outras regiões nacionais.

\section{Dinâmica empresarial regional}

Subjacentes ao estudo empírico da dinâmica empresarial e ao fenómeno do empreendedorismo, estão conceitos e definições de demografia empresarial. É utilizado um léxico próprio, que deriva dos conceitos utilizados no estudo da demografia humana. Assim, a criação de uma empresa é intitulada de nascimento e o seu encerramento é denominado de morte. Consequentemente, o nascimento de uma empresa permite criar emprego e, inversamente, uma morte acarreta a destruição de postos de trabalho. A proporção de novas 
empresas criadas no conjunto de empresas existentes é, deste modo, apelidada de taxa de natalidade, assim como a proporção de empresas encerradas no conjunto de empresas ativas no mercado é designada como taxa de mortalidade.

A criação e destruição de empresas constituem-se como indicadores primários do nível de atividade empreendedora, a nível regional. As Figuras 3 e 4 introduzem a análise da evolução temporal das taxas de natalidade (criação) e mortalidade (encerramento) de empresas. $\mathrm{Na}$ Figura 3 a informação encontra-se detalhada em dois subgrupos de empresas, aquelas com menos de dez trabalhadores e as restantes, dada a elevada representatividade das primeiras no conjunto total de empresas, como verificado na secção anterior.

O somatório destas duas taxas (de mortalidade e de natalidade) permite apurar o grau de dinamismo de um determinado mercado (Eurostat \& OCDE, 2007). Esta taxa fornece uma indicação do nível total de criação e encerramento de empresas, ou seja, de turbulência no mercado empresarial, na medida em que permite aferir a dinâmica estrutural de uma economia, que (potencialmente) dará origem aos denominados fenómenos de "destruição criativa", sobejamente conhecidos da literatura internacional sobre empreendedorismo (OCDE, 2008; Schumpeter, 1934). De acordo com a linha de pensamento Schumpeteriana, o empreendedorismo implica um processo intemporal de criação de novas empresas, crescimento das empresas instaladas e encerramento de empresas mal sucedidas (Batabyal \& Nijkamp, 2012). A taxa de dinâmica empresarial do Algarve é mais elevada do que a média nacional, esbatendo-se o diferencial a partir dos anos 90 (Figura 5).

Figura 3. Comparação da evolução da taxa de natalidade e mortalidade de empresas na região do Algarve e na economia portuguesa entre 1995 e 2007

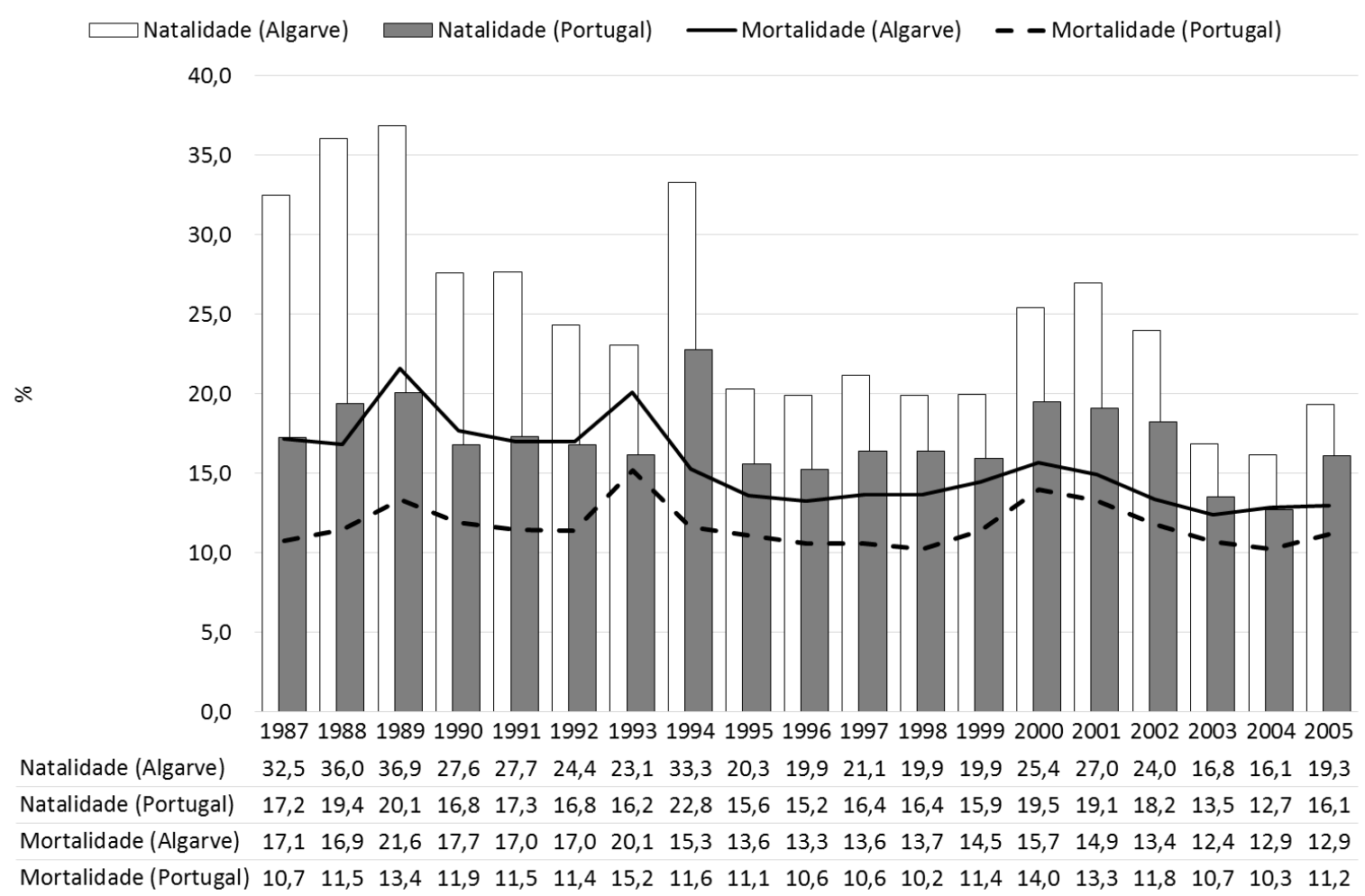

Fonte: Elaboração própria, com base nos Quadros de Pessoal de acordo com as definições do Manual of Business Demography Statistics (Eurostat \& OCDE, 2007). 
Figura 4. Comparação da evolução da taxa de natalidade e mortalidade de empresas - por dimensão - na região do Algarve e na economia portuguesa entre 1995 e 2007
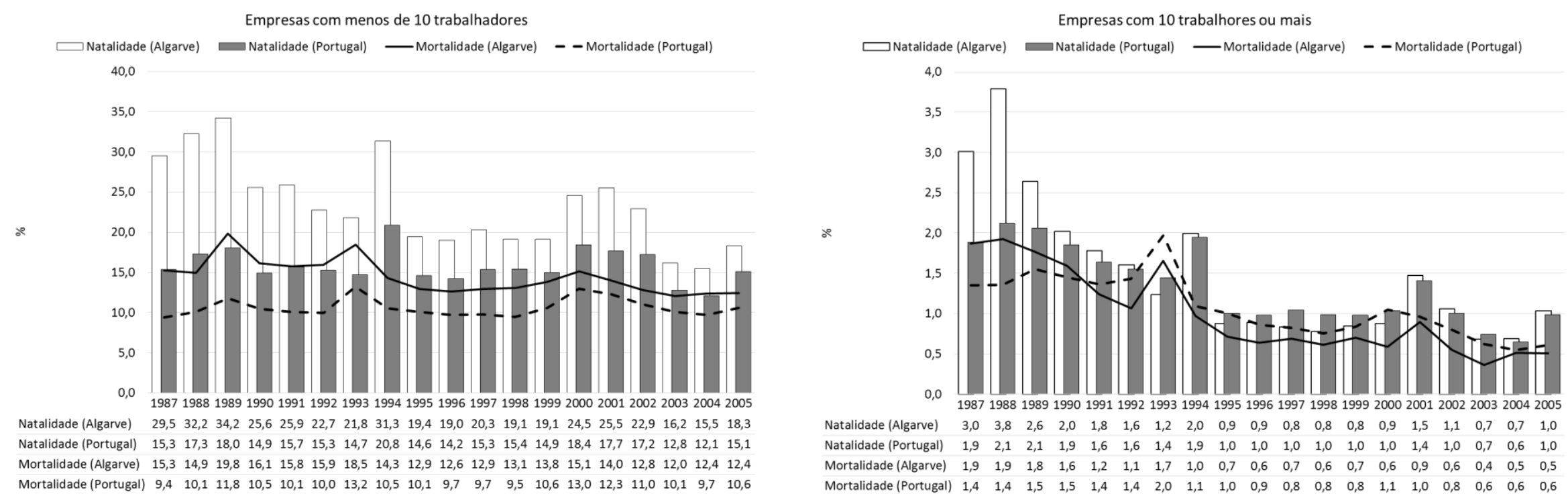

Fonte: Elaboração própria, com base nos Quadros de Pessoal de acordo com as definições do Manual of Business Demography Statistic (Eurostat \& OCDE, 2007)

Tabela 3. Taxa de crescimento médio da taxa de natalidade e mortalidade - por dimensão - na região do Algarve e na economia Portuguesa entre 1995 e 2007

\begin{tabular}{|c|c|c|c|c|c|c|c|c|c|c|c|c|}
\hline Indicador & \multicolumn{6}{|c|}{ Taxa de natalidade } & \multicolumn{6}{|c|}{ Taxa de mortalidade } \\
\hline \multirow{2}{*}{ Dimensão das empresas e região } & \multicolumn{2}{|c|}{ Total } & \multicolumn{2}{|c|}{$0-9$} & \multicolumn{2}{|c|}{10 ou +} & \multicolumn{2}{|c|}{ Total } & \multicolumn{2}{|c|}{$0-9$} & \multicolumn{2}{|c|}{$10 \mathrm{ou}+$} \\
\hline & Algarve & Portugal & Algarve & Portugal & Algarve & Portugal & Algarve & Portugal & Algarve & Portugal & Algarve & Portugal \\
\hline Taxa de crescimento médio & $-2,85$ & $-0,38$ & $-2,62$ & $-0,09$ & $-5,77$ & $-3,52$ & $-1,55$ & 0,22 & $-1,13$ & 0,65 & $-6,99$ & $-4,33$ \\
\hline
\end{tabular}

Fonte: Elaboração própria, com base nos Quadros de Pessoal de acordo com as definições do Manual of Business Demography Statistic (Eurostat \& OCDE, 2007). 
Figura 5. Evolução da dinâmica empresarial do conjunto de empresas empregadoras ativas existentes no Algarve (1987 - 2005)

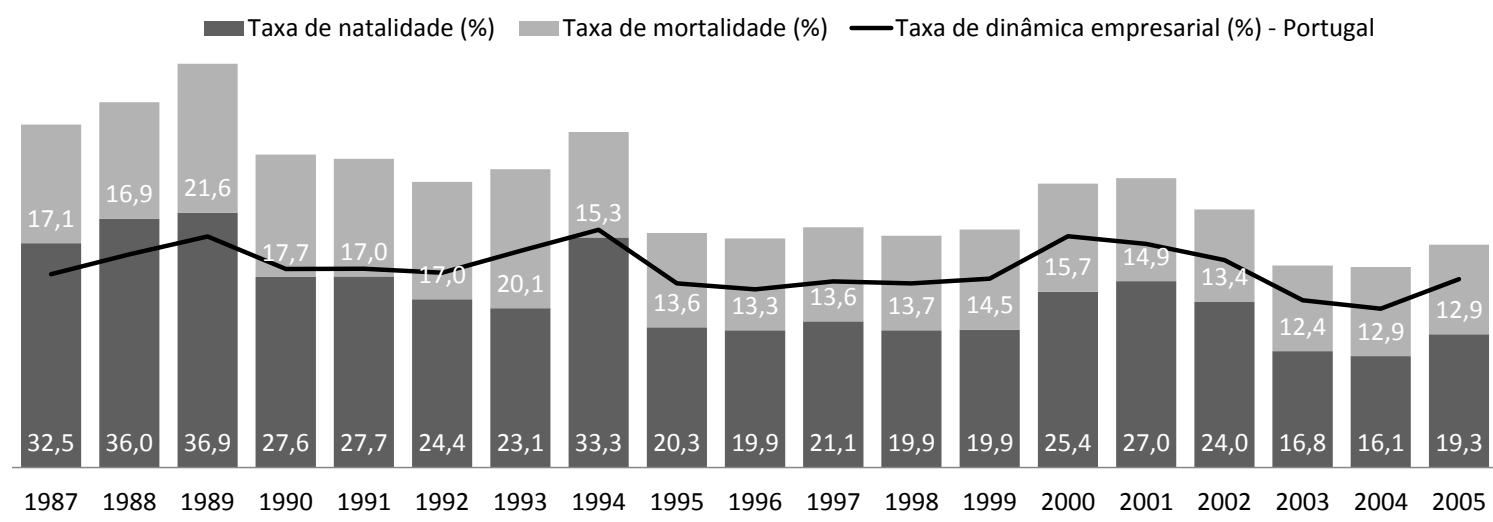

Fonte: Elaboração própria, com base nos Quadros de Pessoal de acordo com as definições do Manual of Business Demography Statistics (Eurostat \& OCDE, 2007).

Dada a existência de elevada correlação entre a criação e a morte de empresas - facto estilizado da demografia empresarial (Cabral, 2007) - a anos de maior criação de empresas correspondem, em geral, anos de maior mortalidade. Os períodos de maior crescimento estão ligados ao ciclo económico e a potenciais efeitos dos diversos quadros comunitários de apoio implementados ao longo deste período (Sarmento \& Nunes, 2012a \& 2012b). Se a Figura 4 permite a visualização da evolução do peso conjunto destas duas taxas em comparação com a dinâmica empresarial da economia, como um todo, a Tabela 4 mostra que a dinâmica empresarial no Algarve também se apresenta como a mais elevada.

Tabela 4. Taxa de dinâmica empresarial por NUT II, em diferentes períodos temporais

\begin{tabular}{ccccccccc}
\hline \multirow{2}{*}{$\begin{array}{c}\text { Taxa de dinâmica } \\
\text { empresarial (\%) }\end{array}$} & Portugal & \multicolumn{7}{c}{ NUT II } \\
\cline { 3 - 9 } & & Algarve & Norte & Centro & Lisboa & Alentejo & Açores & Madeira \\
\hline $1987-2005$ & 28,5 & 32,5 & 29,9 & 27,3 & 26,8 & 29,9 & 27,1 & 28,6 \\
\hline $1987-2000$ & 29,3 & 34,7 & 30,1 & 28,8 & 27,1 & 31,8 & 28,0 & 29,4 \\
$2001-2005$ & 27,3 & 29,4 & 29,4 & 25,1 & 26,2 & 26,6 & 25,5 & 27,3 \\
\hline
\end{tabular}

Fonte: Elaboração própria, com base nos Quadros de Pessoal de acordo com as definições do Manual of Business Demography Statistics (Eurostat \& OCDE, 2007).

A constatação anterior é também corroborada quando a análise é repartida em dois subperíodos. Esta divisão corresponde à perceção de que existem duas tipologias de dinâmica empresarial distintas, a primeira até ao início do século XXI, na qual existe uma elevada dinâmica empresarial, e uma posterior, onde o ritmo de criação e destruição de empresas abranda. Entre 2001 e 2005, esta tendência de redução da turbulência verifica-se de uma forma generalizada no país (Sarmento \& Nunes, 2012a), estando também patente na sua região mais a sul. A taxa de dinâmica empresarial, resultante da soma da taxa de natalidade com a taxa mortalidade, é mais elevada no Algarve do que a média nacional, o mesmo acontecendo para o subconjunto de empresas de menor dimensão. No entanto, no escalão de empresas com mais de dez trabalhadores esta volatilidade é inferior à média nacional para a 
maioria dos anos após 1991.

\section{Criação de emprego no contexto empresarial algarvio em comparação com os valores para o território nacional}

Resultante da maior criação e destruição empresarial apresentada pelo Algarve, também a taxa de criação e destruição de emprego nestas empresas é superior à média nacional (Figura 6), indicando novamente maior turnover e volatilidade de entrada e saída de trabalhadores no mercado de trabalho. ${ }^{5}$ É, também, visível que o diferencial entre as taxas da região e a média nacional, mais acentuadas até meados dos anos 90 do séc. $\mathrm{XX}$, diminui no período posterior. No entanto, enquanto a taxa de criação de emprego se mantém, ainda assim, superior à da média nacional no início do séc. XXI, a taxa de destruição de emprego converge mais rapidamente para a média nacional.

De um ponto de vista mais desagregado, é percetível que o ritmo de crescimento de geração de emprego é mais acentuado nas empresas de média dimensão, em particular nas do escalão entre os dez e os dezanove trabalhadores, entre 1987 e 2000 , e os de vinte a quarenta trabalhadores, após 2000 (Tabela 5).

Tabela 5. Emprego total e crescimento, em média por período, em empresas empregadoras ativas, por dimensão

\begin{tabular}{|c|c|c|c|c|}
\hline \multicolumn{5}{|c|}{ Emprego em empresas empregadoras ativas } \\
\hline \multirow{2}{*}{$\begin{array}{l}\text { Escalão Dimensional } \\
\text { (no trabalhadores) }\end{array}$} & \multicolumn{2}{|c|}{$1987-2000$} & \multicolumn{2}{|c|}{$2001-2005$} \\
\hline & $\begin{array}{c}\text { Média do } n \text { o total de } \\
\text { trabalhadores }\end{array}$ & $\begin{array}{c}\text { Taxa de crescimento } \\
\text { médio }\end{array}$ & $\begin{array}{c}\text { Média do no total de } \\
\text { trabalhadores }\end{array}$ & $\begin{array}{c}\text { Taxa de crescimento } \\
\text { médio }\end{array}$ \\
\hline $1-4$ & 11802 & 11,1 & 24317 & 6,1 \\
\hline $5-9$ & 11182 & 8,3 & 21217 & 4,7 \\
\hline $50-249$ & 13502 & 4,3 & 18776 & 1,9 \\
\hline$\geq 250$ & 3536 & $-0,4$ & 5176 & 5,6 \\
\hline Total & 57512 & 6,5 & 103806 & 4,6 \\
\hline
\end{tabular}

Fonte: Elaboração própria, com base nos Quadros de Pessoal de acordo com as definições do Manual of Business Demography Statistics (Eurostat \& OCDE, 2007).

5 A expressão inglesa revolving door apresenta-se com um significado visual poderoso para a compreensão deste fenómeno. 
Figura 6. Evolução da taxa de criação (absoluta e líquida) e destruição de emprego na região do Algarve e na economia portuguesa entre 1997 e 2005
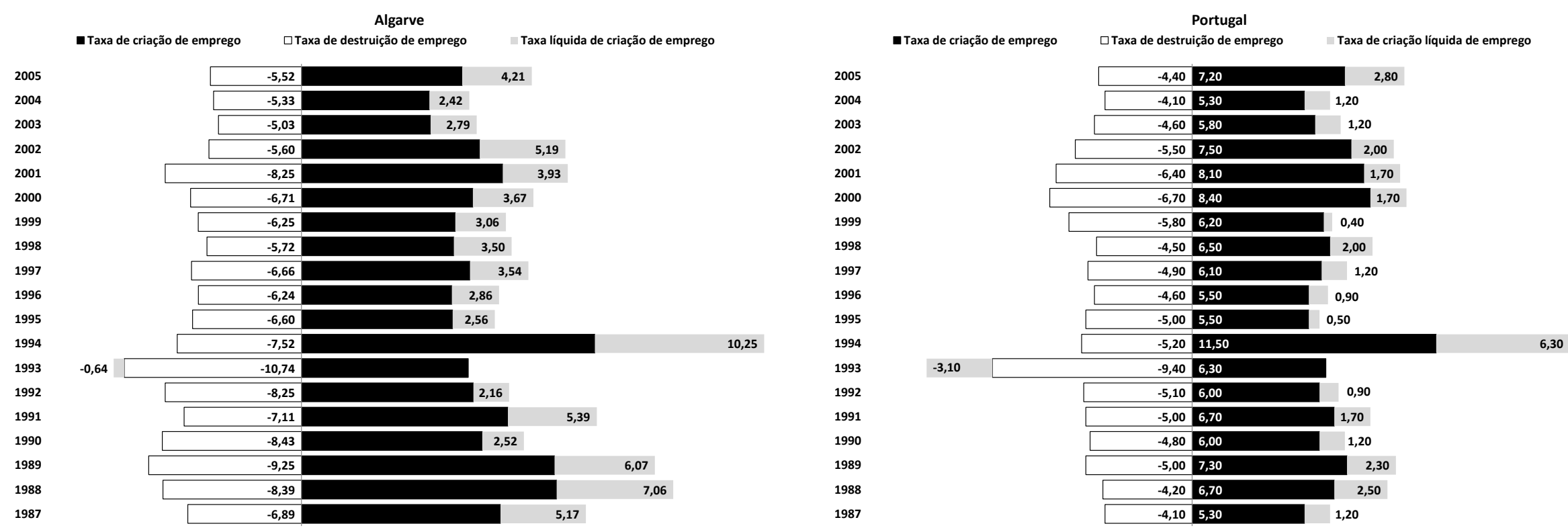

Fonte: Elaboração própria, com base nos Quadros de Pessoal de acordo com as definições do Manual of Business Demography Statistics (Eurostat \& OCDE, 2007). 
No Algarve, uma parte substancial de novo emprego é gerada pela emergência de novas empresas (9,7\%, em 2005). Em particular, em 1994, o ano do início da recuperação económica, após a crise do Sistema Monetário Europeu em 1993 (quando se registou 10,7\% de destruição de emprego), a criação de novas empresas foi responsável por $18 \%$ do emprego sendo, também, este o ano com maior taxa de criação de emprego em empresas já existentes (Figura 7).

Uma análise por dimensão empresarial permite identificar as pequenas empresas com menos de dez trabalhadores, as mais numerosas e que sofrem de maior turbulência, como as responsáveis pela geração de mais postos de trabalho e, igualmente, pela sua destruição. Constata-se que a taxa de criação de emprego diminui à medida que a dimensão aumenta, refletindo a diminuição significativa do número de empresas à medida que o escalão aumenta.

Figura 7. Evolução do emprego líquido, por componente de criação de emprego, de 1987 a 2005

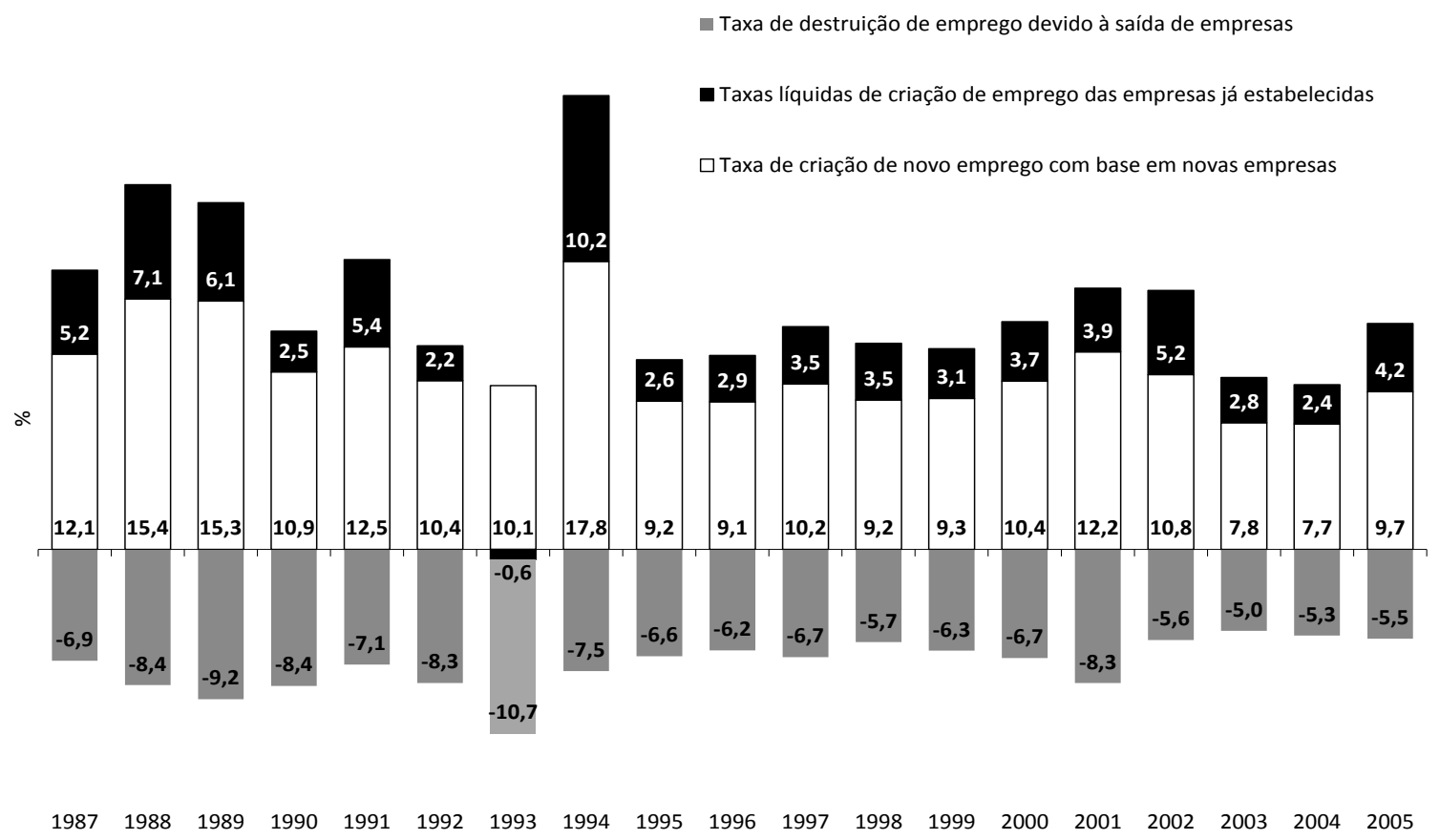

Fonte: Elaboração própria, com base nos Quadros de Pessoal de acordo com as definições do Manual of Business Demography Statistics (Eurostat \&OCDE, 2007).

\section{Por intensidade de crescimento}

Para além dos eventos relacionados com a entrada e saída de empresas do mercado os indicadores referentes ao crescimento das empresas são, também eles, fundamentais para uma análise mais completa do fenómeno do empreendedorismo. O crescimento empresarial tem sido bastante abordado na literatura. No entanto, apenas há cerca de 20 anos surge 0 conceito de empresa "gazela". Esta expressão foi criada por Birch (1979) para designar um pequeno número de empresas de elevado crescimento que gerariam a maior parcela de emprego líquido na economia. Apesar de não existir um acordo claro sobre o que deve designar o termo (Henrekson \& Johansson, 2010) a expressão é utilizada, fundamentalmente, para definir as empresas que são capazes de atingir um ritmo elevado de crescimento num 
curto espaço de tempo. A particularidade das gazelas, e a sua característica identificadora relativamente a uma empresa de elevado crescimento, assenta na natureza e timing do processo de crescimento.

Nesta secção, examina-se a distribuição regional das empresas de elevado crescimento e das gazelas, de acordo com a definição de NUT II e a metodologia adotada neste estudo. Ahmad (2006) e o programa de indicadores de empreendedorismo do Eurostat e da OCDE definem as empresas de elevado crescimento e gazelas de acordo com dois critérios essenciais, por volume de negócios ou emprego (Eurostat \& OCDE, 2007). Consideram-se empresas de elevado crescimento, todas as empresas que tenham tido um crescimento médio anual, em termos de volume de negócios ou emprego, igual ou superior a $20 \%$ ao ano, durante um período de três anos, e que empreguem pelo menos dez trabalhadores no início do período considerado. As gazelas são um subconjunto das empresas de elevado crescimento constituído por empresas jovens que tenham, no máximo, cinco anos de idade (Figura 8).

Figura 8. Definição do universo de empresas de elevado crescimento e de gazelas, por volume de negócios e emprego

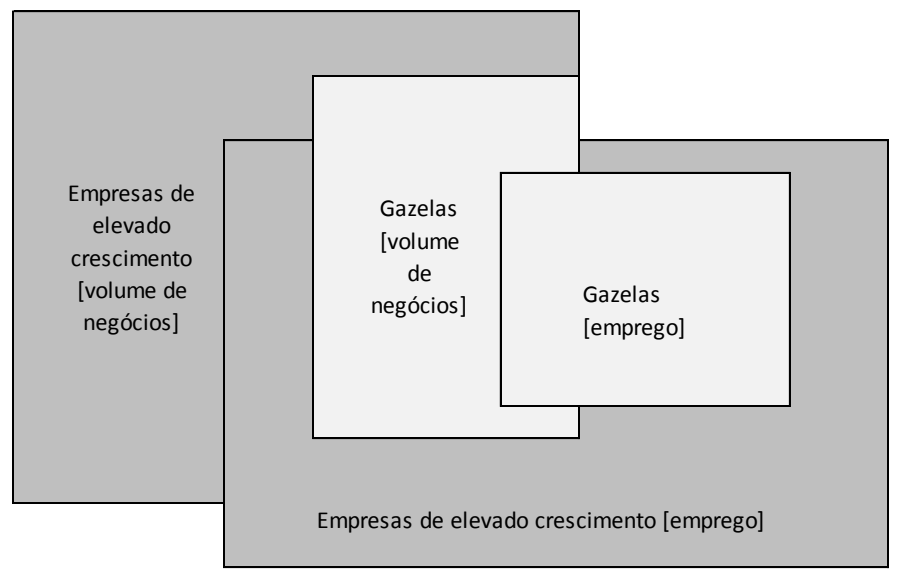

Fonte: Elaboração própria.

A aplicação desta metodologia permite concluir que, por exemplo, das 17.500 empresas existentes no Algarve, em 2004, apenas 73 podem ser consideradas empresas de elevado crescimento em 2007 de acordo com o critério de emprego e apenas 241 de acordo com o critério do volume de negócios (Tabela 6). Por outro lado, das 3.921 empresas com menos de cinco anos, em 2004, apenas vinte e três e setenta e uma podem ser consideradas gazelas, de acordo com o critério de emprego e de volume de negócios, respetivamente (Tabela 7).

Encontram-se empresas de elevado crescimento e gazelas em todas as regiões portuguesas. Em termos absolutos, a região que concentra mais de metade das empresas de elevado crescimento em 2007 é a região de Lisboa. Ao longo deste período, verifica-se uma crescente intensidade de concentração de ambas empresas de elevado crescimento e gazelas na região de Lisboa, enquanto as restantes regiões sofrem de uma diminuição da sua representatividade regional, evidenciando uma ampliação da dicotomia centro/periferia. Este facto é exacerbado quando a análise é feita de acordo com o critério do emprego. Aspetos de localização das sedes das empresas devem também ser tidos em conta numa análise cuidada 
destes dados. A Figura 9, mostra a evolução do peso do emprego em empresas de elevado crescimento em três momentos distintos do período de tempo em estudo - 1990, 2000 e 2007.

Figura 9. Peso do emprego em empresas de elevado crescimento no emprego total em empresas de mais de dez trabalhadores, por NUT II

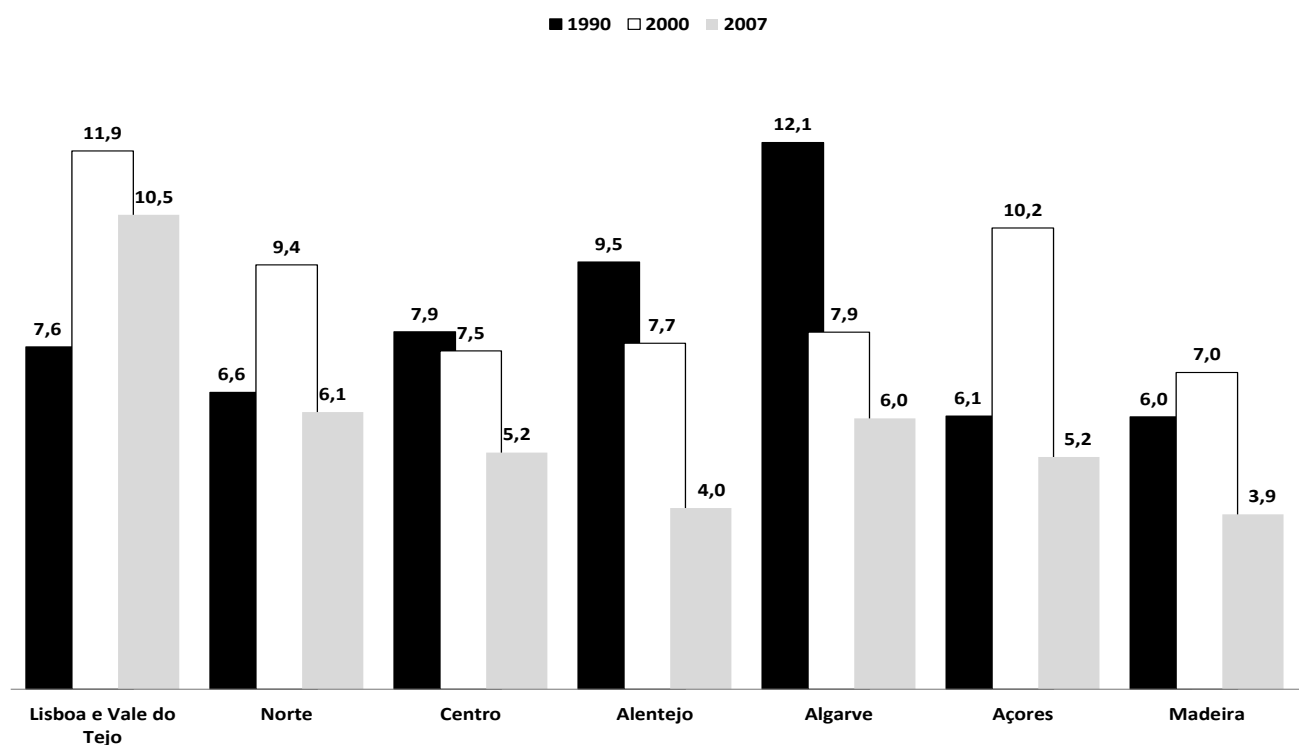

Fonte: Elaboração própria, com base nos Quadros de Pessoal de acordo com as definições do Manual of Business Demography Statistics (Eurostat \& OCDE, 2007).

Em 1990, o emprego nas empresas algarvias de elevado crescimento correspondia a 12,1\% do emprego na região (em empresas com mais de dez trabalhadores), sendo o mais elevado de todas as regiões portuguesas. No entanto, em 2007, a situação reverteu-se, sendo Lisboa a liderar o ranking nacional. $O$ peso do emprego nas empresas de elevado crescimento em Lisboa é quase o dobro de regiões como o Algarve. A proporção deste tipo de emprego no Algarve sofreu a maior quebra de todas as regiões, para cerca de metade em dezassete anos (6\% em 2007).

A análise do conjunto de empresas de elevado crescimento revela um comportamento inverso ao do conjunto do tecido empresarial algarvio, que conseguiu crescer acima da média do crescimento nacional. Em 1990, as empresas algarvias representavam apenas 3\% da população de empresas empregadoras portuguesas, mas em 2007 eram 5,8\%. No entanto, o conjunto de empresas com menos de dez trabalhadores também diminuiu a sua representatividade no conjunto do tecido empresarial, afetando naturalmente a contabilização deste tipo de empresas de rápido crescimento (Tabela 6). Em linha com o verificado para o conjunto de empresas algarvias e nacionais, também estas empresas sofrem uma redução da sua dimensão média (Tabelas 6 e 7). 
Tabela 6. Evolução do número de empresas de elevado crescimento por emprego, no Algarve

\begin{tabular}{|c|c|c|c|c|c|c|c|c|c|c|}
\hline \multirow{4}{*}{ Ano } & \multicolumn{8}{|c|}{ Empresas de elevado crescimento, por emprego } & \multirow[b]{3}{*}{$\begin{array}{l}\text { Dimensão } \\
\text { média }\end{array}$} & \multirow{3}{*}{$\begin{array}{c}\text { Empresas } \\
\text { empregadoras } \\
\text { Proporção de } \\
\text { empresas algarvias } \\
\text { com mais de } 10 \\
\text { trabalhadores }\end{array}$} \\
\hline & & & Empresas & & & & abalhadores & & & \\
\hline & \multirow[t]{2}{*}{ № } & $\begin{array}{c}\text { Taxa de } \\
\text { crescimento }\end{array}$ & $\begin{array}{c}\text { Peso na população } \\
\text { de empresas com } \\
\text { pelo menos } 10 \\
\text { trabalhadores }\end{array}$ & $\begin{array}{c}\text { Taxa de } \\
\text { crescimento }\end{array}$ & № & $\begin{array}{c}\text { Taxa de } \\
\text { crescimento }\end{array}$ & $\begin{array}{c}\text { Peso na população } \\
\text { de empresas com } \\
\text { pelo menos } 10 \\
\text { trabalhadores }\end{array}$ & $\begin{array}{c}\text { Taxa de } \\
\text { crescimento }\end{array}$ & & \\
\hline & & & $\%$ & & & & $\%$ & & № & (\%) \\
\hline 1992 & 28 & $-30,0$ & 2,6 & $-32,2$ & 2358 & $-13,8$ & 6,8 & $-16,6$ & 84,2 & 15,1 \\
\hline 1993 & 34 & 21,4 & 3,2 & 22,0 & 2053 & $-12,9$ & 6,1 & $-10,0$ & 60,4 & 14,4 \\
\hline 1994 & 29 & $-14,7$ & 2,6 & $-20,2$ & 1863 & $-9,3$ & 5,7 & $-7,5$ & 64,2 & 13,1 \\
\hline 1995 & 25 & $-13,8$ & 2,2 & $-13,7$ & 1424 & $-23,6$ & 4,3 & $-24,3$ & 57,0 & 12,5 \\
\hline 1996 & 27 & 8,0 & 2,3 & 4,8 & 2306 & 61,9 & 6,7 & 56,4 & 85,4 & 12,1 \\
\hline 2001 & 89 & 27,1 & 4,5 & 3,9 & 6083 & 66,5 & 11,1 & 39,9 & 68,3 & 13,3 \\
\hline 2002 & 90 & 1,1 & 4,3 & $-4,4$ & 4524 & $-25,6$ & 8,2 & $-25,7$ & 50,3 & 12,8 \\
\hline 2003 & 70 & $-22,2$ & 3,3 & $-23,7$ & 4566 & 0,9 & 7,9 & $-4,2$ & 65,2 & 12,6 \\
\hline 2004 & 62 & $-11,4$ & 2,9 & $-13,6$ & 3404 & $-25,4$ & 5,7 & $-27,3$ & 54,9 & 12,3 \\
\hline 2005 & 49 & $-21,0$ & 2,1 & $-25,9$ & 2324 & $-31,7$ & 3,6 & $-36,8$ & 47,4 & 12,2 \\
\hline 2006 & 54 & 10,2 & 2,3 & 6,8 & 3012 & 29,6 & 4,5 & 23,1 & 55,8 & 12,1 \\
\hline 2007 & 73 & 35,2 & 2,8 & 22,3 & 4490 & 49,1 & 4,3 & $-3,4$ & 61,5 & 12,7 \\
\hline
\end{tabular}

Fonte: Elaboração própria, com base nos Quadros de Pessoal de acordo com as definições do Manual of Business Demography Statistics (Eurostat \& OCDE, 2007).

Enquanto as empresas de elevado crescimento diminuem o seu peso no tecido empresarial entre 1990 e 2007, o Algarve é a única região do país onde as gazelas conseguem recuperar a sua representatividade, mantendo-se em 2007, em cerca de $1 \%$ da população total de empresas com mais de dez trabalhadores (Tabela 7). Apesar do aumento do número de empresas de elevado crescimento (cinquenta e três em 1990 e setenta e três em 2007), a região perde relevância no contexto nacional, dado que essas cinquenta e três empresas representavam em 1990, 5,4\% do total nacional, mas em 2007 representavam apenas cerca de metade da proporção inicial (2,8\%). O mesmo acontece com o número de trabalhadores que cai, em média, ainda mais em resultado da diminuição da dimensão média não só das empresas de elevado crescimento como das gazelas. Em quinze anos, as gazelas perdem dezassete trabalhadores e as empresas de elevado crescimento cerca de onze trabalhadores. 
Tabela 7. Evolução do número de gazelas por emprego, no Algarve

\begin{tabular}{|c|c|c|c|c|c|c|c|c|c|}
\hline \multirow[b]{3}{*}{ Ano } & \multicolumn{9}{|c|}{ Gazelas, por emprego } \\
\hline & \multicolumn{4}{|c|}{ Empresas } & \multicolumn{4}{|c|}{ Trabalhadores } & \multirow[b]{2}{*}{$\begin{array}{c}\text { Dimensão } \\
\text { média }\end{array}$} \\
\hline & № & $\begin{array}{c}\text { Taxa de } \\
\text { crescimento }\end{array}$ & $\begin{array}{l}\text { Peso na população } \\
\text { de empresas com } \\
\text { pelo menos } 10 \\
\text { trabalhadores }\end{array}$ & $\begin{array}{c}\text { Taxa de } \\
\text { crescimento }\end{array}$ & № & $\begin{array}{c}\text { Taxa de } \\
\text { crescimento }\end{array}$ & $\begin{array}{l}\text { Peso na população } \\
\text { de empresas com } \\
\text { pelo menos } 10 \\
\text { trabalhadores }\end{array}$ & $\begin{array}{c}\text { Taxa de } \\
\text { crescimento }\end{array}$ & \\
\hline 1993 & 13 & 30,0 & 1,3 & 24,2 & 632 & 0,2 & 1,9 & $-5,7$ & 48,6 \\
\hline 1994 & 10 & $-23,1$ & 0,9 & $-25,5$ & 660 & 4,4 & 1,9 & 1,0 & 66,0 \\
\hline 1995 & 5 & $-50,0$ & 0,5 & $-49,8$ & 205 & $-68,9$ & 0,6 & $-67,9$ & 41,0 \\
\hline 1996 & 7 & 40,0 & 0,6 & 31,0 & 323 & 57,6 & 1,0 & 60,6 & 46,1 \\
\hline 1997 & 7 & 0,0 & 0,6 & 0,1 & 643 & 99,1 & 1,9 & 97,2 & 91,9 \\
\hline 2001 & 18 & 38,5 & 1,2 & 23,8 & 1275 & 107,3 & 3,0 & 87,7 & 70,8 \\
\hline 2002 & 19 & 5,6 & 1,2 & $-1,9$ & 604 & $-52,6$ & 1,3 & $-56,4$ & 31,8 \\
\hline 2003 & 11 & $-42,1$ & 0,6 & $-52,7$ & 408 & $-32,5$ & 0,7 & $-43,2$ & 37,1 \\
\hline 2004 & 20 & 81,8 & 1,0 & 71,9 & 922 & 126,0 & 1,7 & 125,7 & 46,1 \\
\hline 2005 & 16 & $-20,0$ & 0,8 & $-21,5$ & 566 & $-38,6$ & 1,0 & $-41,7$ & 35,4 \\
\hline 2006 & 18 & 12,5 & 0,8 & 9,7 & 773 & 36,6 & 1,3 & 33,1 & 42,9 \\
\hline 2007 & 23 & 27,8 & 1,0 & 19,7 & 1051 & 36,0 & 1,6 & 25,8 & 45,7 \\
\hline
\end{tabular}

Fonte: Elaboração própria, com base nos Quadros de Pessoal de acordo com as definições do Manual of Business Demography Statistics (Eurostat \& OCDE, 2007).

\section{A sobrevivência e o encerramento}

A compreensão dos fenómenos subjacentes às dinâmicas de nascimento, crescimento e encerramento de empresas revela-se fundamental para o desenvolvimento equilibrado de políticas de desenvolvimento regional que possam apoiar devidamente a atividade empresarial, bem como a criação e manutenção de novo emprego. Na literatura académica existem alguns estudos empíricos que analisam a relação entre fatores regionais e o encerramento de empresas. Carree, Verheul e Santarelli (2011), por exemplo, referem que as infraestruturas são ativos fundamentais para o desenvolvimento do potencial económico de uma região permitindo que se utilizem, eficientemente, os recursos disponíveis para a atividade empresarial.

A análise da probabilidade de sobrevivência das empresas na região do Algarve, ao longo dos anos disponíveis neste estudo (1985-2007), utiliza o estimador não paramétrico de KaplanMeier. Entende-se como probabilidade de sobrevivência de uma empresa, a probabilidade de esta sobreviver (não encerrar) para além de um determinado período de tempo $t$, condicionada pelo facto de ter sobrevivido (isto é, de se ter mantido ativa) até esse mesmo momento. Este tipo de metodologia tem-se tornado familiar e tem-se revelado de extrema utilidade na literatura dedicada à sobrevivência de empresas (para um resumo de exemplos da aplicação da metodologia pode consultar-se Manjón-Antolín \& Arauzo-Carod, 2008), sendo já conhecidos alguns estudos para a economia portuguesa, em geral, e para a região Norte, em particular (Nunes \& Sarmento, 2012; Sarmento \& Nunes, 2011). A análise e discussão da probabilidade de sobrevivência das empresas localizadas numa determinada região apresenta 
particular importância, não só do ponto de vista da performance empresarial, como também de um ponto de vista de desenvolvimento regional. O encerramento de uma empresa comporta consequências óbvias para o mercado de trabalho, com a destruição de postos de trabalho.

Na Tabela 8 é possível observar os resultados do estimador Kaplan-Meier, considerando o conjunto de empresas criadas de 1987 a 2005. Para além dos resultados estimados referentes à probabilidade de sobrevivência, apresenta-se ainda o número de empresas observadas, o número de empresas encerradas e o número de empresas não encerradas. Do conjunto de 25.192 empresas criadas no período, verifica-se que cerca de $86 \%$ se mantém ativa após o primeiro ano de vida, descendo este valor para os $75 \%$, após mais um ano de atividade. Após dezoito anos da sua criação, apenas cerca de $24 \%$ das empresas algarvias se mantêm ainda em atividade. Nesta região, $50 \%$ das empresas morre entre os cinco e os seis anos de vida, em linha com a média nacional (Tabela 8).

Tabela 8. Probabilidade de sobrevivência das empresas no Algarve

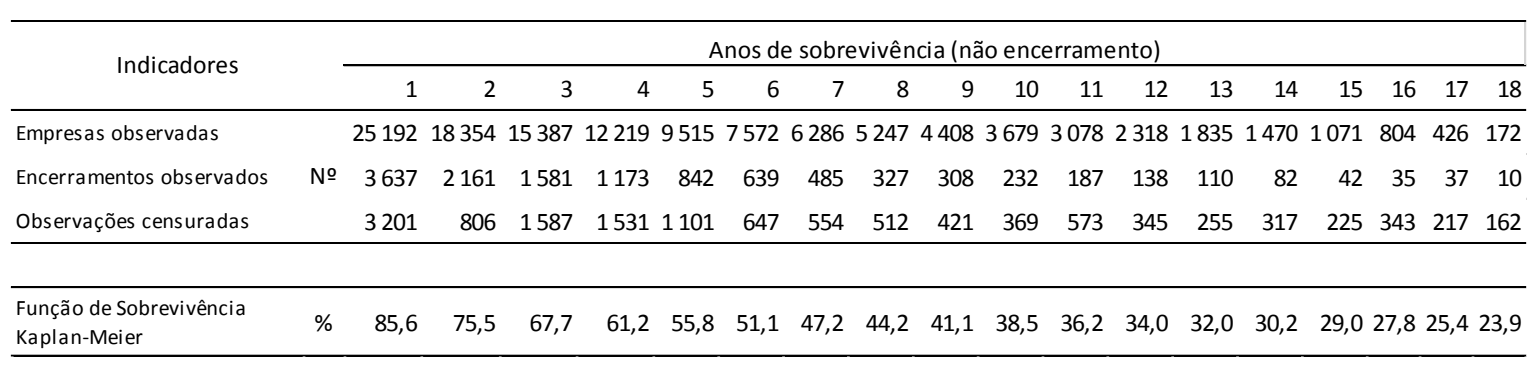

Fonte: Elaboração própria, com base nos Quadros de Pessoal de acordo com as definições do Manual of Business Demography Statistics (Eurostat \& OCDE, 2007).

Comparando as taxas de sobrevivência empresarial no Algarve com as taxas de sobrevivência empresarial nas restantes NUTs II portuguesas, visíveis na Tabela 9, é possível completar a análise regional comparada de sobrevivência de empresas empregadoras. A performance agregada de sobrevivência das empresas na região do Algarve não aparenta ser tão problemática como a de outras regiões, nomeadamente a região Norte, que sofre de problemas específicos ligados às características do seu tecido empresarial e à maior predominância de atividade industrial (Sarmento \& Nunes, 2011). É no entanto mais débil que a região que revela melhor capacidade de sobrevivência, a região Centro.

Tabela 9. Probabilidade de sobrevivência das empresas, por NUT II (\%)

\begin{tabular}{|c|c|c|c|c|c|c|c|c|c|c|c|c|c|c|c|c|c|c|}
\hline \multirow{2}{*}{ NUT II } & \multicolumn{18}{|c|}{ Anos de sobrevivência (não encerramento) } \\
\hline & 1 & 2 & 3 & 4 & 5 & 6 & 7 & 8 & 9 & 10 & 11 & 12 & 13 & 14 & 15 & 16 & 17 & 18 \\
\hline Norte & 85,6 & 75,1 & 66,5 & 59,8 & 54,1 & 49,4 & 45,3 & 41,7 & 38,7 & 35,8 & 33,0 & 30,5 & 28,1 & 26,4 & 24,8 & 23,2 & 21,9 & 20,7 \\
\hline Centro & 87,4 & 77,7 & 70,1 & 64,0 & 58,9 & 54,5 & 50,7 & 47,5 & 44,5 & 41,9 & 39,5 & 37,4 & 35,3 & 33,4 & 31,8 & 30,4 & 28,9 & 27,4 \\
\hline Lisboa & 85,5 & 75,1 & 67,0 & 60,5 & 55,0 & 50,4 & 46,6 & 43,2 & 40,2 & 37,6 & 35,1 & 32,8 & 30,8 & 29,0 & 27,4 & 26,1 & 24,6 & 22,9 \\
\hline Madeira & 86,1 & 76,0 & 68,3 & 61,3 & 56,2 & 51,6 & 47,5 & 44,6 & 41,7 & 38,6 & 36,6 & 34,3 & 31,7 & 29,9 & 28,2 & 26,9 & 26,6 & 25,4 \\
\hline
\end{tabular}

Fonte: Elaboração própria, com base nos Quadros de Pessoal de acordo com as definições do Manual of Business Demography Statistics (Eurostat \& OCDE, 2007). 


\section{Conclusões}

A discussão sobre a mudança de paradigma público de apoio à criação de start-ups para o apoio a empresas de elevado crescimento é uma realidade, dada a constatação empírica que um pequeno número de empresas cria uma proporção significativamente mais elevada de emprego que um grande número de pequenas e médias empresas (Coad, Daunfeldt, Hölzl, Johansson \& Nightingale, 2014). Tendo este impacto económico como ponto de partida, têm sido desenvolvidos diversos estudos sobre a taxa de crescimento de empresas, entre os quais os que versam sobre o Reino Unido, Suécia ou Espanha (Daunfeldt \& Halvarsson, 2015; Mason \& Brown, 2013; Lopez-Garcia \& Puente, 2012). A seleção do conjunto de variáveis analisado neste trabalho - que procurou identificar tendências de evolução ao longo de cerca de vinte anos de estudo - inspira-se em estudos recentes efetuados em outras economias e regiões, em particular as que vêm desenvolvendo políticas públicas de promoção da criação de empresas e da sua sustentabilidade.

Este estudo revela que tomadas de decisão sobre o tecido empresarial, por políticos ou outros decisores, devem considerar para além da quantidade, a qualidade do crescimento empresarial.

O Algarve tornou-se a região do país com a maior taxa de criação de empresas empregadoras a partir do ano 2000. Foi igualmente a região com o mais elevado crescimento da população de empresas no período considerado. A partir de 1998, a sua densidade empresarial cresceu sustentadamente, visto o ritmo de crescimento empresarial ser superior ao da população da região. Em 2007, 67,7\% das empresas empregavam menos de vinte trabalhadores, o que corresponde a $58,4 \%$ do emprego na região.

No entanto, o Algarve revelou ter perdido ao longo do tempo, e relativamente a outras regiões, a sua capacidade de criar ou atrair empresas de elevado crescimento. Isto é, apesar do número absoluto de empresas de elevado crescimento e respetivos trabalhadores ter aumentado no período, a região perdeu expressão no contexto nacional. Em 1990, o emprego nas empresas de elevado crescimento correspondia a 12,1\% do emprego na região (o mais elevado de todas as regiões portuguesas) tendo sofrido porém a maior quebra regional - o seu valor passou para cerca de metade em dezassete anos (6\% em 2007).

Se a criação de empresas possui um impacto considerável numa determinada região, a sua capacidade de sobrevivência não será de menosprezar. Com o desaparecimento de empresas, perdem-me empregos e interrompe-se o processo de introdução de inovações e de geração de riqueza. Sabe-se que a especialização produtiva de uma região pode ser determinante na capacidade de sobrevivência e sustentabilidade das empresas. Existem estudos, como por exemplo os de Gémar, Moniche e Morales (2016) e de Brouder e Eriksson (2012), que abordam a sobrevivência de empresas na indústria do turismo, sector particularmente relevante para a região algarvia.

Ainda no que diz respeito à sobrevivência, constatou-se que no Algarve, 50\% das empresas encerraram entre os cinco e os seis anos de vida, valor próximo da média de sobrevivência de empresas a nível nacional. Mas após dezoito anos, apenas $24 \%$ das empresas se mantiveram em atividade. A análise de sobrevivência empresarial entre regiões revela que, apesar do desempenho das empresas algarvias não ser tão positivo como o da região Centro, não apresentou os problemas de outras regiões, mais afetadas por reestruturações do seu setor industrial. O peso substancial das pequenas e médias empresas, que era o mais elevado 
do país, foi a principal causa da elevada turbulência empresarial da região, sendo que a dimensão média das empresas algarvias caiu substancialmente ao longo do período em estudo.

Sendo este um trabalho eminentemente exploratório, deixa o ensejo de que em trabalhos futuros se investiguem as causas e implicações da evolução das variáveis apresentadas. No entanto, é importante salientar que se apresenta uma análise de duas décadas da demografia empresarial no Algarve, fundamentais para compreender o desenvolvimento económico e empresarial mais recente desta importante região do país.

\section{Referências bibliográficas}

Acs, Z. \& Storey, D. J. (2004). Introduction: Entrepreneurship and economic development. Regional Studies, 38(8), 871-877. doi: 10.1080/0034340042000280901.

Ahmad, N. \& Seymour, R. G. (2008). Defining Entrepreneurial Activity: Definitions Supporting Frameworks for Data Collection. OCDE Statistics Working Papers, 2008/01, OCDE Publishing. doi: $10.1787 / 18152031$.

Ahmad, N. (2006). A proposed framework for business demography statistics. In E. Congregado (Ed.). Measuring Entrepreneurship (chapter 7: pp.113-174). Springer. doi: 10.1007/978-0-387-72288-7_7.

Armington, C. \& Acs, Z. J. (2002). The determinants of regional variation in new firm formation. Regional Studies, 36(1), 33-45. doi: 10.1080/00343400120099843.

Audretsch, D. B. (2007). Entrepreneurship capital and economic growth. Oxford Review of Economic Policy, 23(1), 63-78. doi: 10.1093/oxrep/grmoo1

Audretsch, D. B., Bönteb, W. \& Keilbach, M. (2008). Entrepreneurship capital and its impact on knowledge diffusion and economic performance. Journal of Business Venturing, 23(6), 687-698. doi: 10.1016/j.jbusvent.2008.01.006.

Barbosa, N. \& Eiriz, V. (2011). Regional variation of firm size and growth: the Portuguese case. Growth and Change, 42 (2), 125-158. doi: 10.1111/j.1468-2257.2011.00547.x

Batabyal, A \& Nijkamp, P. (2012). A Schumpeterian model of entrepreneurship, innovation, and regional economic growth. International Regional Science Review, 35, 339-361. doi: 10.1177/0160017611429701.

Batista, R. \& Preto, M. T. (2011). New firm formation and employment growth: regional and business dynamics. Small Business Economics, 36(49), 419-442. doi: 10.1007/s11187-009-9254-y.

Batista, R. \& Mendonça, J. (2010). Proximity to knowledge sources and the location of knowledgebased start-ups. The Annals of Regional Science, 45(1), 5-29. doi: 10.1007/s00168-009-0289-4.

Batista, R., Escária, V. \& Madruga, P. (2008). Entrepreneurship, regional development and job creation: the case of Portugal. Small Business Economics, 30(1), 49-58. doi: 10.1007/s11187-007-9055-0.

Baumgartner, D., Pütz, M. \& Seidl, I. (2013). What kind of entrepreneurship drives regional development in European non-core regions? A literature review on empirical entrepreneurship research. European Planning Studies, 21(8), 1095-1127. doi: 10.1080/09654313.2012.722937.

Birch, D. L. (1979). The job generation process. MIT Program on neighborhood and regional change, MIT: Cambridge, MA.

Bosma, N. \& Sternberg, R. (2014). Entrepreneurship as an urban event? Empirical evidence from European cities. Regional Studies, 48(6), 1016-1033. doi: 10.1080/00343404.2014.904041.

Brixy, U. \& Grotz, R. (2007). Regional patterns and determinants of birth and survival of new firms in Western Germany. Entrepreneurship \& Regional Development: An International Journal, 19(4), 293312. doi: $10.1080 / 08985620701275510$.

Brouder, P. \& Eriksson, R. H. (2012). Staying power: what influences micro-firm survival in Tourism? Tourism Geographies, 15, 125-144. doi: 10.1080/14616688.2011.647326.

Cabral, L. (2007). Small firms in Portugal: A selective survey of stylized facts, economic analysis and policy implementation. Portuguese Economic Journal, 6(1), 65-88. doi: 10.1007/s10258-007-0018-9.

Cabral, L. \& Mata, J. (2003). On the evolution of the firm size distribution: facts and theory. The American Economic Review, 93(4), 1075 - 1090.

Carree, M. A., Verheul, I. \& Santarelli, E. (2011). Sectoral patterns of firm exit in Italian provinces. Journal of Evolutionary Economics, 21(3), 499-517. doi: 10.1007/s00191-010-0191-3. 
Coad, A., Daunfeldt S.-O., Hölzl, W., Johansson, D. \& Nightingale, P. (2014). High-growth firms: Introduction to the special section. Industrial and Corporate Change, 23(1), 91-112. doi: 10.1093/icc/dtt052.

Daunfeldt, S.-O. \& Halvarsson, D. (2015). Are high-growth firms one hit wonders? Evidence from Sweden. Small Business Economics, 44, 361-383. doi: 10.1007/s11187-014-9599-8.

Eurostat \& OCDE (2007). Eurostat - OECD Manual on Business Demography Statistics.

Gémar, G., Moniche, L. \& Morales, A. J. (2016). Survival analysis of the Spanish hotel industry. Tourism Management, 54, 428-438. doi: 10.1016/j.tourman.2015.12.012.

Geroski, P. A., Mata, J. \& Portugal, P. (2010). Founding conditions and the survival of new firms. Strategic Management Journal, 31(5), 510-529. doi: 10.1002/smj.823.

Henrekson, M. \& Johansson, D. (2010). Gazelles as job creators: A survey and interpretation of the evidence. Small Business Economics, 35(2), 227-244. doi: 10.1007/s11187-009-9172-z.

Kibler, E. (2012). Formation of entrepreneurial intentions in a regional context. Entrepreneurship \& Regional Development: An International Journal, 293-323. doi: 10.1080/08985626.2012.721008.

Instituto Nacional de Estatística [INE] (2008).Destaque: Contas Regionais 2006 Definitivas \& 2007 Preliminares. Consultado em www.ine.pt.

Lopez-Garcia, P. \& Puente, S. (2012). What makes a high-growth firm? A dynamic probit analysis using Spanish firm-level data. Small Business Economics, 39, 1029-1041. doi: 10.1007/s11187-011-9321-z.

Malecki, E. J. (2009). Geographical environments for entrepreneurship. International Journal of Entrepreneurship and Small Business, 7(2), 175-190. doi: 10.1504/IJESB.2009.022805.

Manjón-Antolín, M. C. \& Arauzo-Carod, J.-M. (2008). Firm survival: Methods and evidence. Empirica, 35(1), 1-24. doi: 10.1007/s10663-007-9048-x.

Mason, C. \& Brown, R. (2013). Creating good public policy to support high-growth firms. Small Business Economics, 40, 211-225. doi: 10.1007/s11187-011-9369-9.

Mata, J. (1993). Entry and type of entrant: evidence from Portugal. International Journal of Industrial Organization, 11(1), 101-122. doi:10.1016/0167-7187(93)90038-E.

Mata, J. \& Portugal, P. (1994). Life duration of new firms. The Journal of Industrial Economics, 42(3), 227245 .

Mata, J., Portugal, P. \& Guimarães, P. (1995). The survival of new plants: Start-up conditions and postentry evolution. International Journal of Industrial Organization, 13(4), 459-481. doi.org/10.1016/0167-7187(95)00500-5.

Naudé, W. A., Gries, T., Wood, E. \& Meintjes, A. (2008). Regional determinants of entrepreneurial startups in a developing country. Entrepreneurship and Regional Development, 20(2), 111-124. doi: $10.1080 / 08985620701631498$

Nunes, A. \& Sarmento, E. M. (2012). Business demography dynamics in Portugal: A non-parametric survival analysis. In J. Bonnet, M. Desjardin \& A. Madrid-Guijarro, (Eds), The Shift to the Entrepreneurial Society: a Built Economy in Education, Sustainability and Regulation, (Chapter 18: 260-272), Edward Elgar Publishing.

Nunes, A. \& Sarmento, E. M. (2010). Business Survival in Portuguese Regions. GEMF Working Papers, 22/2010, Faculdade de Economia da Universidade de Coimbra, Coimbra: Portugal.

Nyström, K. (2007). An industry disaggregated analysis of the determinants of regional entry and exit. The Annals of Regional Science, 41(4), 877-896. doi: 10.1007/s00168-007-0130-x.

OCDE (2009). Measuring Entrepreneurship. A Collection of Indicators 2009 Edition. OECD Statistics Directorate. Disponível em http://www.insme.org/files/3862.

OCDE (2008). Measuring Entrepreneurship: A Digest of Indicators. OECD Statistics Directorate. Disponível em http://hermes-osr.eu/attachments/230_oecd-indicators-report.pdf.

Santarelli, E. \& Vivarelli, M. (2007). Entrepreneurship and the process of firms' entry, survival and growth. Industrial and Corporate Change, 16(3), 455-488. doi: 10.1093/icc/dtmo10.

Sarmento, E. M. \& Nunes, A. (2012a). Employer enterprises in Portugal: Size distribution dynamics. In J. Bonnet, M. Desjardin, \& A. Madrid-Guijarro (Eds), The Shift to the Entrepreneurial Society: a Built Economy in Education, Sustainability and Regulation, (Chapter 17: 242-259), Edward Elgar Publishing.

Sarmento, E. M. \& Nunes, A. (2012b). Criação de empresas em Portugal e Espanha no período 20002007: Análise Comparativa com base no World Bank Global Entrepreneurship Survey (WBGES), Tourism \& Management Studies, 8, 116-131.

Sarmento, E. M. \& Nunes, A. (2011). Análise comparativa de sobrevivência empresarial: O caso da região norte de Portugal. Revista Portuguesa de Estudos Regionais, 25/26, 77-93. 
Sternberg, R. (2012). Do EU regional policies favour regional entrepreneurship? Empirical evidence from Spain and Germany. European Planning Studies, 20(4), 583-608. doi: 10.1080/09654313.2012.665030.

Sternberg, R. (2010). Regional dimensions of entrepreneurship. Foundations and Trends in Entrepreneurship, 5(4), 211-340. doi: 10.1561/0300000024.

Schumpeter, J. A. (1934). The Theory of Economic Development. Harvard University Press: Cambridge.

Trettin, L. \& Welter, F. (2011). Challenges for spatially oriented entrepreneurship research. Entrepreneurship \& Regional Development: An International Journal, 23(7-8), 575-602. doi: $10.1080 / 08985621003792988$.

Van Dijk, J. \& Pellenbarg, P. H. (2000). The demography of firms: progress and problems in empirical research. In J. van Dijk \& P.H. Pellenbarg (Eds), Demography of Firms; Spatial Dynamics of Firm Behaviour (Chapter 17: 325-337), Netherlands Geographical Studies 262.

Agradecimentos

Agradece-se aos participantes no $14 .^{\circ}$ Workshop da APDR "Empreendedorismo e Desenvolvimento Regional" no qual uma versão preliminar deste trabalho foi apresentada.

ElSA DE Morais SaRmento exerce atividade de docência há mais uma década em economia e econometria, tendo sido investigadora no Centre for Economic Performance (LSE) em Inglaterra e no Parlamento Europeu, entre outros. Anteriormente trabalhou para o Banco Mundial, Banco Africano de Desenvolvimento, Nações Unidas e respetivas instituições, União Europeia e Organisation of Eastern Caribbean States. Desempenhou diversos trabalhos de assessoria em matéria de política económica e relações internacionais na Câmara dos Comuns (Reino Unido), para diversos Governos Africanos, tendo tido igualmente exercido diversos cargos de direção no Ministério da Economia de Portugal.

Alcina Nunes é doutorada em Economia Matemática e Modelos Econométricos e Professora Coordenadora no Departamento de Economia e Gestão do Instituto Politécnico de Bragança, onde leciona nas áreas da Economia e Gestão e assume a Direção da licenciatura em Gestão de Negócios Internacionais, e investigadora no Grupo de Estudos Monetários e Financeiros (GEMF) da Faculdade de Economia da Universidade de Coimbra. Prestou serviços no Gabinete de Estratégia e Estudos do Ministério da Economia (Portugal) como investigadora na área da demografia de empresas. Tem desenvolvido atividades de investigação na área da Economia Aplicada (avaliação de políticas do mercado de trabalho e da saúde) e Empreendedorismo.

Submetido em 12 fevereiro 2015

Aceite em 24 fevereiro 2016 